\title{
A imagem da Revolução Russa pela mídia regional no Paraná ${ }^{1}$
}

\author{
Sergio Luiz GADINI ${ }^{2}$
}

\begin{abstract}
Resumo:
O texto, em formato ensaístico, discute notícias veiculadas pelo jornal Diário dos Campos (o DC, editado desde 1907, na região dos Campos Gerais do Paraná) sobre a Revolução Russa e os desdobramentos em alguns dos momentos que marcaram o ano de 1917, tendo por base as informações publicadas pelo periódico. A análise das notícias dialoga com a perspectiva de produções editoriais: jornalismo como base de pesquisa (PONTES; SILVA, 2012) e as características estruturais como base de análise editorial (GADINI, 2010). A leitura metodológica das notícias veiculadas no DC considera as principais marcas estruturais do modo de se fazer jornalismo na época (início do século XX), levando em conta as especificidades contextuais das condições em que o Diário dos Campos era editado em 1917. As imagens reproduzidas no corpo do texto, aliadas aos aspectos observados na leitura metodológica do jornal, possibilitam compreender os limites estruturais de uma produção jornalística diária no interior do Paraná, que circulava em uma cidade de 20 mil habitantes, mas com leitores também em outros municípios dos Campos Gerais.

Palavras-chave:

Jornalismo regional. Jornalismo impresso. Memória. Diario dos Campos. 100 anos da Revolução Russa.
\end{abstract}

\section{The image of the Russian Revolution by regional media in Paraná}

\begin{abstract}
:
The text, in an essay format, discusses news published by Diário dos Campos newspaper (DC, published since 1907, in the Campos Gerais region of Paraná) about the Russian Revolution and the developments in some of the moments that marked the year 1917, based on the information published by the journal. The analysis of the news talks with the perspective of editorial productions: journalism as a research base (PONTES, SILVA, 2012) and the structural characteristics as a basis for editorial analysis (GADINI, 2010). The methodological reading of the news published in the DC considers the main structural marks of the way of making journalism at the time (beginning of century XX), allied to the contextual specificities of the conditions in which Diário dos Campos was published in 1917. The reproduced images in the body of the text, together with the aspects observed in the methodological reading of the newspaper, make it possible to understand the structural limits of daily journalistic production in the interior of Paraná, which circulated in a city of 20 thousand inhabitants, as well as readers in other municipalities of Campos Gerais.

Keywords:

Regional journalism. Pinted journalism. Memory. Diario dos Campos. 100 years of the Russian Revolution.
\end{abstract}

\section{La imagen de la Revolución Rusa por los medios regionales en Paraná}

\section{Resumen:}

El texto, en formato ensayístico, discute las noticias transmitidas por el Diário dos Campos (o DC, editado desde 1907, en la región de los Campos Generales de Paraná) sobre la Revolución Rusa y los desdoblamientos en algunos de los momentos que marcaron el año 1917, sobre la base de la información publicada por el periódico. El análisis de las noticias dialoga con la perspectiva de producciones editoriales: periodismo como base de investigación (PONTES; SILVA, 2012) y las características estructurales como base de análisis editorial (GADINI, 2010). La lectura metodológica de las noticias transmitidas en el DC considera las principales marcas estructurales del modo de hacer periodismo en la

\footnotetext{
${ }^{1}$ Uma versão preliminar deste texto foi apresentada no painel "100 anos da Revolução Russa: mídia, imaginários, representações e temores", durante o XI Encontro Nacional de História da Mídia (ALCAR), realizado na Universidade Presbiteriana Mackenzie, em São Paulo/SP, entre os dias 8 e 10 de Junho de 2017.

${ }^{2}$ Professor da Universidade Estadual de Ponta Grossa (UEPG). E-mail: slgadini@uepg.br
} 
época (principios del siglo XX), aliado a las especificidades contextuales de las condiciones en que el Diario de los Campos era editado en 1917. Las imágenes reproducidas en el cuerpo del texto, aliado a los aspectos observados en la lectura metodológica del periódico posibilitan comprender los límites estructurales de una producción periodística diaria en el interior del Paraná, que circulaba en una ciudad de 20 mil habitantes, además de lectores en otros municipios de los Campos Generales.

Palabras clave:

Periodismo regional. Periodismo impreso. Memoria. Diario dos Campos. 100 años de la Revolución Rusa.

\section{Apontamentos (contextuais) preliminares}

Se procede a máxima de que os registros históricos são dos próprios vencedores parece razoável entender porque as inegáveis conquistas do maior movimento de resistência e luta dos trabalhadores dos últimos séculos tenha caído no vazio ou já se encontram poucos capazes de defender a contribuição. Também por isso, é preciso lembrar - e discutir - os 100 anos da Revolução Russa registrados em 2017.

A disputa em torno do significado da Revolução Russa registra, na prática, o tempo físico equivalente ao século histórico decorrido, pois as imagens e representações - desde o primeiro ano do movimento e ao longo do século - revelam as dimensões de uma guerra em torno dos riscos e interpretações que transformações outras poderiam decorrer, no mundo todo, na vida e condições de trabalho da grande maioria que, até hoje, só possui uma moeda no mercado da sobrevivência capitalista: a força do trabalho humano!

É nesse contexto que se pode situar, e compreender, as escolhas editoriais do jornal Diário dos Campos (a partir daqui indicado pela sigla DC), um dos principais do interior do Paraná no início do século XX, sobre alguns acontecimentos que marcaram a Revolução Russa, tendo por base o ano inaugural do histórico movimento sóciopolítico. Tais escolhas, como se pode verificar pelas notas e informações veiculadas, não eram aleatórias, mas, guardadas as proporções, faziam parte de uma disputa em curso sobre modos de pensar e agir, que marcaram a adesão, simpatia ou rejeição imaginária a (quase) tudo que, nos anos seguintes, iriam se referir aos desdobramentos e significados da principal revolução comandada por um partido criado a partir da proposta de defesa dos interesses da maioria dos trabalhadores.

Oportuno situar que a Revolução não surgiu por acaso de um destino incerto e tampouco da cabeça de dirigentes de um partido - de orientação assumidamente marxista - que apostou no convencimento conceitual da maioria de seus possíveis adeptos. As condições reais de vida e trabalho dos protagonistas do movimento, ou seja, 
os próprios trabalhadores e trabalhadoras, foram a base social onde se desenvolveu e gestou todo o processo revolucionário.

Alguns acontecimentos revelam a dimensão contextual da época: um destes é o Dia Internacional da Mulher, 8 de março (pelo calendário ocidental) ou 23 de fevereiro de 1917 (pelo calendário russo czarista)!

\begin{abstract}
Aquel día frio, pero soleado, decenas de miles de trabajadoras de las fábricas de Petrogrado salieron de los suburbios, cruzaron el río Neva y se adentraron por la interminable Perspectiva Nevski. Reivindicaban una subida salarial y el fin de la participación rusa en la Primera Guerra Mundial (...). Imaginaban que, como era habitual bajo el reinado del buenazo de Nicolás II, decenas de ellas saldrarían muertas o malheridas del trance (...). Cuando al fin aparecieron los cosacos, estos se negaron a obedecer las órdenes de sus superiores: dispersarlas a toda costa. Asi comenzó la Revolución Rusa, en concreto su primer acto, la Revolución de Febrero. (VALENZUELA, 2017, p. 38).
\end{abstract}

Contudo, à exceção dos periódicos de aliados ou partidários das causas revolucionárias, em geral a partir dos partidos comunistas ou obreiros, não era essa a imagem mais habitual que ganhava as páginas dos impressos, ao longo das primeiras décadas do século XX.

Apesar do silêncio midiático hegemônico, habitual em praticamente todos os produtos impressos sob controle empresarial, fagulhas do movimento revolucionário saíram da Rússia e conquistavam alguma simpatia na resistência, em especial, por parte de trabalhadores, que viviam dilemas similares da exploração capitalista vigente. E, assim, aconteceu a primeira grande greve em dezenas de cidades do Brasil, em junho de 1917.

O que se reivindicava no movimento? Entre as bandeiras, além do aumento salarial, destaca-se a "redução das jornadas de trabalho, que até então não eram garantidos por lei. Em algumas semanas, a greve se espalharia por diversos setores da economia, por todo o Estado de São Paulo e, em seguida, para o Rio de Janeiro e Porto Alegre. Era a primeira 'greve geral' no país", explica Camilla Costa (2017, não paginado). Os movimentos sociais no Brasil viviam, então, a efervescência de ideias socialistas, anarco-sindicalistas e também comunistas, em geral, defendidas por trabalhadores migrantes que chegavam às diversas cidades brasileiras, desde o final do século XIX. 
Variáveis e limites de um retrato de mídia regional em 1917

A Revolução Russa é, para a maioria dos historiadores, compreendida e estudada em duas etapas. A primeira, com a derrubada do Czar Nicolás (ou Nicolau) II, diante da pressão de trabalhadores, campesinos e desempregados, que rumaram ao palácio, cobrando ações contra o aumento da miséria e pobreza, também decorrente da opção pela guerra, que causou a morte de milhares de soldados russos. A Revolução de fevereiro de 1917 - março, de acordo com calendário ocidental - resultou na criação de um governo provisório, sob o comando do general Alexander Kerensky, que assumiu implantar ações políticas para reduzir a pobreza, tais como a redução da jornada de trabalho aos padrões europeus da época (oito horas diárias), liberdade de imprensa, anistia aos presos políticos do regime czarista, dentre outras lutas populares. O Partido Bolchevique não chega, contudo, a apoiar a transição, apostando na construção do projeto popular autônomo.

A segunda etapa é a Revolução de Outubro (ou 6 de novembro, de acordo com o calendário vigente), por meio dos Sovietes (conselhos populares), sob comando de Lenin, que passa a implantar medidas de socialização e controle popular dos principais meios de produção, em sintonia com as crescentes demandas de trabalhadores urbanos, desempregados e campesinos.

O presente estudo apresenta um recorte e análise do material publicado pelo Diário dos Campos sobre a fase mais tensa da Revolução, o período entre julho e dezembro de 1917. O DC é um dos poucos periódicos impressos que registram circulação diária no Paraná e o único no interior do Estado Além disso, os Campos Gerais teriam, em tese, um público virtualmente interessado no assunto, uma vez que, desde o final do século XIX, a região passa a receber levas de trabalhadores migrantes, originários da Rússia e leste Europeu, tais como ucranianos, alemães das proximidades do Rio Volga, poloneses, dentre outros grupos étnicos.

Mesmo sendo a maior cidade da região, Ponta Grossa possui pouca estrutura e população urbana. De acordo com Elizabete Alves Pinto (1980, p. 54), entre 1877 e 78 a região de Ponta Grossa recebeu 2381 imigrantes russos-alemães, dos 3809 que entraram na Província (PR). Em 1917, a população de Ponta Grossa era estimada em 20 mil habitantes (PINTO, 1980, p. 61).

Arquivos confirmam que, em 1917, poucos jornais circulavam com edição diária no Paraná. Embora seja estranho comparar, por variadas razões e indicadores, a capital 
do Paraná registra, na segunda década do século (1911-20) mais diários em circulação do que registra hoje, 100 anos depois. No período, ainda que com algumas interrupções de periodicidade, circulavam em Curitiba o Commercio do Paraná, o Diário da Tarde, A Noite, a Tribuna e A República, que era o órgão oficial do Estado. Entre os jornais diários que circulavam no interior do Estado, o mais expressivo, talvez pela influência regional e socioeconômica da cidade, era o Diário dos Campos, em Ponta Grossa.

Existiam ainda outros impressos, mas que tinham periodicidade mais larga ou mesmo eventual. Já no interior do Estado, a situação era ainda mais incipiente, pois apenas em Ponta Grossa havia um periódico com circulação cotidiana: o Diário dos Campos, criado em 1907 como O Progresso e, poucos anos depois, passando a ser Diário dos Campos, com edição diária.

Naquele momento, o Diário dos Campos era um periódico modesto em estrutura, mas com uma circulação praticamente diária, exceto aos domingos. Não há informação precisa sobre a tiragem do periódico, mas estima-se que oscilava entre 500 ou 1000 exemplares ao dia. Em formato standard, o DC possuía quatro páginas e, em alguns raros momentos, circulava com duas ou seis páginas. Na ocasião, o editor era o jornalista Hugo dos Reis, intelectual de prestígio na Cidade, o que lhe conferia uma espécie de condição de porta-voz dos interesses comunitários nas escolhas e ações editoriais cotidianas. Aos domingos, "a folha não roda", como informava o periódico na capa.

É importante considerar o contexto que marca o jornalismo brasileiro no início do século XX para, assim, entender o que e como se faz jornal no interior do Paraná, a partir do DC. Regra geral, os periódicos não usavam imagem (a não ser chapas de personagens públicas, disponíveis para chapar em tinta e projetar o impresso em preto e branco). Boa parte das notas e textos assinados em forma de análise ou comentário sobre situação internacional é oriunda de agências noticiosas via telegrama. O mesmo vale para temas nacionais, que são enviados principalmente a partir do Rio de Janeiro, capital federal. Com menor frequência, temas regionais são recebidos da capital do Estado, Curitiba. Informações de pesquisadores e historiadores locais (PINTO, 1980; BUCHOLDZ, 2007; PONTES; GADINI, 2011) indicam que o DC era produzido basicamente por duas ou três pessoas, embora majoritariamente pelo diretor-editor. Os assuntos locais são pautados do cotidiano da cidade, por demanda e contato pessoal ao editor, relatos de eventuais colaboradores de municípios da região, que levavam até a 
sede do jornal, além de boletins de ocorrência policial, quando considerados impactantes aos moradores.

De um modo geral, no jornalismo do início do século XX no Brasil, e mais habitualmente fora das principais capitais, não há preocupação conceitual com fontes ou pluralidade na abordagem dos fatos. A primeira página abre com uma espécie de texto autoral, em forma de editorial, segue com telegramas que chegam ao jornal até o fim da tarde anterior, fecham-se rodapés de páginas com inserções oucalhaus, que convidam para assinar, colaborar ou divulgar o DC. Na última página, em geral, estão os anúncios comerciais, chamadas oficiais de clubes sociais e convites para atividades consideradas de interesse público.

Para este estudo foram destacados alguns textos e notas que falam da Revolução Russa, de forma mais presente, divulgados entre julho e dezembro de 1917 quando, além do acirramento da disputa interna e atuação dos revolucionários, o governo brasileiro decreta entrada na guerra mundial e, aí, a Rússia - sob o comando de Alexander Kerensky -, que combate a expansão do império austro-alemão, é considerada parcialmente aliada, pois o Brasil também declara guerra e, à distância, envia apoio na forma de suprimentos e declarações oficiais, alertando para a necessidade de conter o avanço germânico. Nesse contexto, no ano da revolução, a Rússia é mais habitualmente pauta nas páginas do DC.

A versão editorial veiculada pelo DC é, portanto, filtrada pelo editor, que assume a condição de simpatizante da entrada do Brasil na guerra e passa a propagandear ações de crítica e mesmo ataque aos migrantes e descendentes de alemães que vivem na região de Ponta Grossa. Pelas notas, a Rússia seria aliada e, pois, mais frequentemente destacada por suas ações militares contra os alemães. A abordagem metodológica, portanto, considera esse contexto do jornalismo brasileiro, tendo por base as principais características e estratégias editoriais mais frequentes na época da edição do DC e do período observado (1917).

A análise dos materiais publicados toma por base dois eixos que dialogam com a perspectiva de produções editoriais: a produção noticiosa como base de pesquisa (PONTES; SILVA, 2012) e as características estruturais e contextuais do jornalismo como base de análise editorial (GADINI, 2010). Assim, a leitura metodológica das notícias veiculadas no DC considera as principais marcas estruturais do modo de se fazer jornalismo na época (início do século XX), levando em conta as especificidades 
contextuais das condições em que o Diário dos Campos era editado em 1917. As imagens reproduzidas no corpo do texto, aliadas aos apontamentos e aspectos observados na leitura metodológica do jornal, possibilitam compreender os limites estruturais de uma produção jornalística diária no interior do Paraná.

\section{A Revolução que faz 100 anos}

Em fevereiro de 1917 (março, pelo calendário ocidental), depois de uma série de protestos e manifestações populares nas principais cidades do País, a Rússia registra o fim do governo do czar Nicolau II e instaura um governo provisório, sob comando de Alexandre Kerensky. Membro da ala menchevique do Partido Socialista, Kerensky defende as regras do modelo capitalista de desenvolvimento como estratégia de transição ao socialismo. A gestão acaba em novembro, quando a ala mais popular do Partido Socialista, os bolcheviques, liderados por Vladimir Lenin, toma o governo e passa a implantar um programa assumidamente socialista com metas de coletivização gradual do então decadente sistema feudal, em que cerca de $80 \%$ da população vivia no meio rural.

O objetivo, aqui, não é contar uma história da Revolução Russa, mas é inevitável situar alguns aspectos para mapear o cenário da época. E, para isso, uma referência -

pela vida, experiência e registro - é a análise de Leon Trotsky (1977), principalmente o texto em forma de conferência apresentado em 1932, durante evento organizado pela Associação dos Estudantes Social-Democratas de Copenhague.

Para compreender a cobertura jornalística veiculada por agências noticiosas em 1917, é oportuno lembrar que a Rússia saiu da $1^{\text {a }}$ Guerra Mundial no mesmo ano em que explodiu a Revolução. "Até a guerra, o partido bolchevique pertenceu à socialdemocracia internacional", afirma Trotsky (1977, p. 44). Mas, em 4 de agosto de 1914, segundo o mesmo autor (1977, p. 44), “o voto da social-democracia alemã a favor dos créditos de guerra acabou de uma vez para sempre com esta unidade e abriu a era da luta incessante e intransigente do bolchevismo contra a social-democracia".

“A Rússia foi o primeiro país a deixar o campo de batalha. Mas para se retirar da guerra, o povo russo precisou derrubar as classes dominantes”, conta Trotsky (1977, p. 50). Era, pois, a suspensão, ainda que temporária, da máxima "trabalhadores, uni-vos em tempos de paz; guerreai-vos em tempos de guerra", que ironicamente pautava os movimentos e partidos da social-democracia europeia até as primeiras décadas do século XX e, em menor grau, também na eclosão da segunda guerra (1939-45). 
Vale lembrar que o Partido Bolchevique foi criado em 1912, sob a liderança de Vladimir Ulianov (Lenin), depois de uma longa cisão, que surgiu em 1903, com os mencheviques. Até então, as duas alas pertenciam ao Partido Operário SocialDemocrata Russo, criado em 1898, em assembleia clandestina.

No que diz respeito à cobertura do DC sobre a guerra, é, portanto, compreensível porque e como as notícias chegavam ao interior do Paraná e também aos mais diversos municípios brasileiros em 1917, focando relatos de batalhas da tal primeira guerra mundial (que, de 1914, prolonga um incontável e impreciso registro de perdas humanas, até 1918). Não é isso, pois, que interessa ao presente texto. Assim, os eventuais telegramas noticiosos sobre batalhas, envolvendo tropas russas na guerra imperialista, não entram, aqui, como recorte do que a imprensa regional veiculou ao longo do histórico ano de 1917.

Mas, "como é que num país atrasado pôde triunfar a revolução socialista?", pergunta o ex-chefe do exército vermelho soviético, e o próprio responde: "No desenvolvimento das nações e dos estados, em particular dos estados capitalistas não há nem semelhança nem uniformidade. Diferentes graus de cultura - e até pólos opostos aproximam-se e combinam-se muitas vezes na vida de um único país" (TROTSKY, 1977, p. 51).

Assim, resume o cenário do atraso russo no início de 1917, segundo o mesmo autor (1977, p. 52): “A indústria ocupa no país um lugar mínimo em relação ao campo, a cidade em relação ao campo, o proletariado em comparação com o campesinato". Em indicadores, Trotsky (1977, p. 52) traduz: “Quase sem estradas nacionais, a Rússia viuse obrigada a construir caminhos de ferro. Sem ter passado pelo artesanato e pela manufatura europeias, a Rússia passou diretamente para as empresas mecanizadas. O futuro dos países atrasados é saltar etapas intermédias".

Outro fator foi decisivo nas condições potenciais de mudança social. "O proletariado jovem, fresco, resoluto, não constituía contudo mais do que uma minoria ínfima da nação. As reservas da sua potência revolucionária encontravam-se fora do próprio proletariado: no campesinato, que vivia numa semi-escravidão e nas nacionalidades oprimidas" (TROTSKY, 1977, p. 53). E, ainda Trotsky (1977, p. 54): "No Outono de 1917, quase todo o país estava envolvido pelo levantamento camponês. De 624 distritos da velha Rússia 482, isto é, 77\%, eram atingidos pelo movimento. O reflexo de aldeias incendiadas iluminava a arena do levantamento nas cidades". 
As inevitáveis resistências ao fortalecimento da revolução tinham, obviamente, motivos e interesses sustentados na condição socioeconômica dos grupos hegemônicos da fase anterior:

\begin{abstract}
A burguesia liberal russa não queria, nem na questão nacional, nem na questão agrária, ir além de certas reformas para atenuar o regime de opressão e de violência. Os governos 'democráticos' de Milioukov e de Kerensky, que exprimiam os interesses da burguesia e da burocracia grão-russa, apressaramse, no decurso dos oito meses da sua existência, a fazer compreender às nações descontentes: "não obtereis senão aquilo que arrancardes pela força". (TROTSKY, 1977, p. 56).
\end{abstract}

Os acontecimentos da luta construída pelos trabalhadores foram indicando alguns dos importantes passos da transformação: "Sem a insurreição armada de 25 de outubro de 1917 (7 de novembro segundo o calendário atual) o Estado soviético não existiria. Mas a insurreição não caiu do céu. Para a Revolução de Outubro era necessário uma série de premissas históricas”, defende Trotsky (1977, p. 59).

O Partido Bolchevique comandou a insurreição de outubro "com um cálculo frio e uma firme resolução. Graças a isso triunfou quase sem vítimas. Por meio de sovietes vitoriosos, os bolcheviques colocaram-se à cabeça do país que engloba um sexto da superfície terrestre", explica Trotsky (1977, p. 62). Mas, isso estava longe da paz para governar! "Os donos do mundo armavam-se contra o primeiro Estado Operário: início da guerra civil, novas e novas intervenções, bloqueios. Assim passou ano após ano. A história registrou, entretanto, 15 anos de existência do poder soviético", diz o autor de $A$ Revolução Permanente, em 1932. Como se vê, a Revolução Russa não se resumiu em ocupar o Palácio de Inverno, em São Petersburgo!

\title{
Diário dos Campos edita acontecimentos da Revolução Russa
}

O estudo buscou textos ou notas veiculadas no DC durante o ano que marcou a Revolução Russa. As edições disponíveis no acervo são de março a dezembro de 2017. A ênfase foca o segundo semestre (julho a dezembro), quando a presença de milhares de soldados russos na guerra - contra a Alemanha - ganha registro em forma de conquista contra o avanço do império austro-germânico.

Um olhar nacionalista a serviço de governos entreguistas! Esta é a marca de boa parte dos periódicos (diários ou não) que circulam no Brasil no início do século $\mathrm{XX}$ (LARANGEIRA, 2017). Nos Campos Gerais do Paraná, onde o Diário é um dos poucos com edição diária do Estado, a situação não é diferente. Na tradição hegemônica jornalística da época, tensionada por limitadas estruturas de apuração com poucos 
profissionais, baixos orçamentos e um número modesto de leitores assíduos, os periódicos dependem basicamente do telégrafo, que reenvia notas de agências noticiosas e também de materiais já publicados em jornais das principais cidades do País (a então capital federal Rio de Janeiro e São Paulo, além de eventuais notas da capital do Estado, Curitiba). No mais, os jornais eram feitos por duas ou três pessoas, que ouviam relatos de moradores, registravam solenidades oficiais na cidade, reproduziam boletins policiais considerados impactantes, além de eventuais colaboradores, que dedicavam algum tempo aos periódicos em troca de um suposto prestígio intelectual.

Ainda assim, há que se destacar, o DC é um dos poucos periódicos que mantêm edição e circulação diária no ano em que os trabalhadores tomam o governo russo e anunciam a construção de um estado socialista.

Do início de julho até meados de agosto de 1917, o DC segue praticamente uma mesma orientação editorial. As tropas russas (aliadas) eram incensadas nos textos e notas veiculadas pelo jornal, que reproduzia telegramas recebidos. "Retirada austroallemã. Petrogrado, 5 - Os austro-allemães evacuaram Brzezansky, a sudoeste de Lemberg, ante a impetuosa avançada dos exércitos russos que tem por objetivo a tomada daquela praça" (RETIRADA..., 1917, p.1).

Na edição de 14 de agosto de 1917, telegrama publicado pelo DC informa protesto russo contra tratamento alemão aos presos (de guerra). E em texto em formato de editorial na primeira página, o DC de 13 de agosto aborda a democracia russa. O texto fala em democracia a partir de um elogio ao então dirigente do governo provisório, Alexandre Kerensky, nomeado como “o grande!". "Kerensky no momento atual, é o homem para que se volta ancioso e palpitante o sonho da revolução. Tudo se lhe entrega às mãos em desmaios e esperanças...”, diz o texto. 


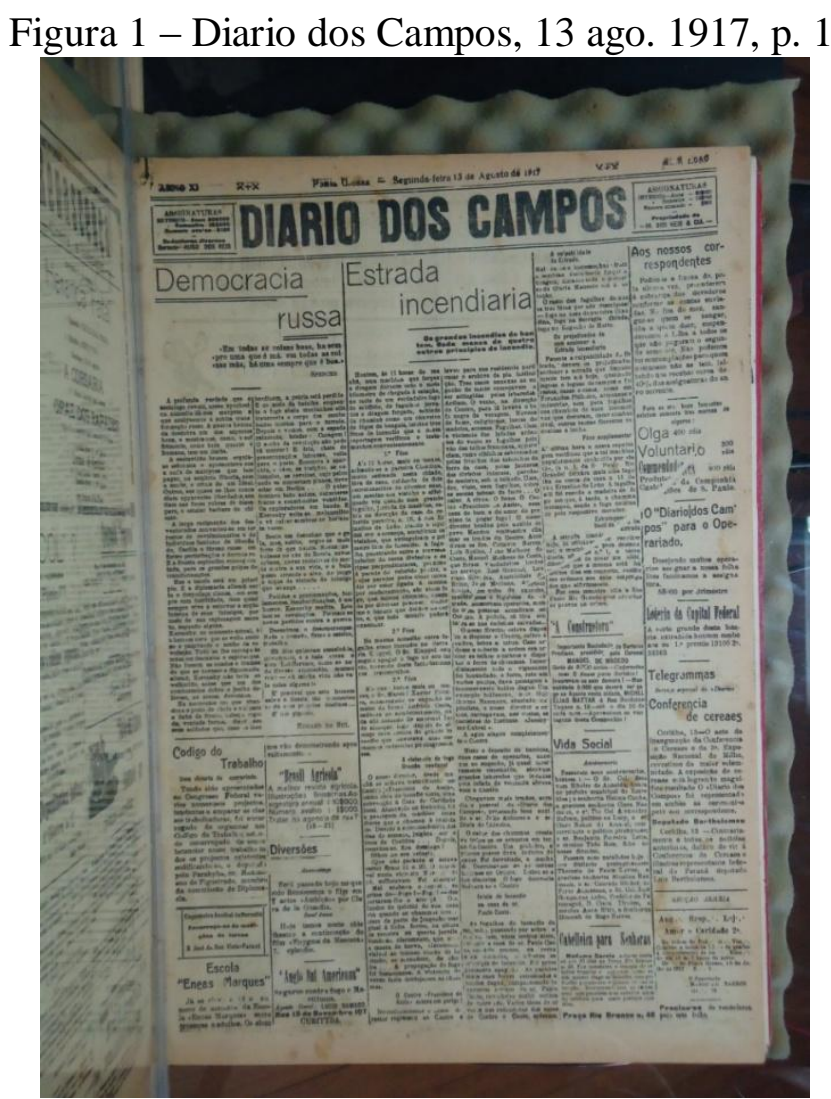

Fonte: Acervo Casa da Memória PG (reprodução).

A edição do DC que circula na segunda-feira, 10 de setembro de 1917, reproduz as notas telegráficas a partir de New York. Na primeira, o título informa que "Dvinski resistirá - O Coronel Podjeresky, comandante russo da Praça forte de Dvinsky telegrafou ao governo de Petrogrado dizendo que resistirá até a última extremidade contra os alemães".

A segunda nota aborda disputas internas. "A situação russa. Nova York, 10 - O governo russo estabeleceu rigorosa censura, decidindo que os jornais publiquem somente os telegramas officiaes sobre a guerra. Foram suspensos vários jornais contrarevolucionários". Como se vê, a gestão de transição (ditatorial) mostra uma outra face: censura aos que os impressos deveriam ou poderiam publicar sobre a guerra, que há anos matava milhares de soldados russos!

Na edição de 11 de setembro de 1917, o Diário informa, em nota, na capa, reproduzindo telegrama: "A situação na Russia: importante proclamação do grande estadista Kerensky. Petrogrado, 11 - O SrKerensky, chefe do governo russo, mandou affixar a seguinte proclamação, explicando ao povo moscovita as razões que o levaram à destituição do general Kornillof do cargo de chefe supremo do exército...”. Em 14 de 
setembro, o DC repercute o assunto e informa: "Kerensky venceu (...) o general-rebelde Korniloff". No dia seguinte (15 de setembro), outra nota repercute o tema: "Korniloff arrependido". "O general revoltoso, Korniloff, tentou suicidar-se", relata telegrama de Petrogrado.

Por fim, em 27 de setembro, o DC informa que Korniloff fora absolvido: "New York, 27 - Annunciam de Washington ter sido absolvido o General Korniloff por ter ficado provado a má enterpretação dada ao acordo feito entre esse e o General Kerensky". Como se vê, as guerras não se vencem apenas na batalha física, mas na forma como se informa e repercute atos governistas, trocas de comando, negociações, dentre outras iniciativas. Em tempos de pouca informação disponível, ao que tudo indica, periódicos eram sugeridos a reproduzir notas prontas que vinham do serviço de agências informativas.

Na edição de 10 de outubro de 1917, o DC informa nota de agência que tem por título Greve na Rússia: "Odessa, 10 - O governo russo resolveu conceder o augmento de salario aos empregados ferroviários que se achavam em greve.” Em 19 de outubro, o DC informa, sob o título Mais uma derrota alemã:

Petrogrado, 19 - Os alemães durante a madrugada tentaram lançar uma ponte sobre o rio Dvina, percebido porém, a artilharia russa fez debandar inutilizando o esforço e trabalho alemão. As tropas alemães desembarcaram na ilha Dago, foram porém pela guarnição russa atacadas e derrotadas, precipitadamente reembarcando tiveram grandes perdas de material bélico e homens. (MAIS..., 1917, p. 1).

Em 26 de outubro de 1917, o governo brasileiro declara guerra à Alemanha (DC, 26 e 27 de outubro de 1917). Daí em diante, no ano, a cobertura foca mais ações governistas e menos telegramas (internacionais). Daí em diante, o DC foca "o Brasil na guerra!", inclusive com bisbilhotagens e incentivo a um comportamento antigermânico. Boa parte das notícias, em formato telegráfico, vem de Petrogrado... E relatam derrotas militares dos alemães.

Em 05 de novembro, o DC informa que a Rússia estaria saindo da guerra. Na mesma edição, uma chamada destaca que o governo brasileiro chama o povo para a guerra. Na edição de 07 de novembro, o próprio editor do jornal (Hugo Reis) assina nota, na capa, convidando os "polacos partidários dos aliados" para reunião aberta na cidade. 
Figura 2 - Diario dos Campos, 5 nov. 1917, p.1. Figura 3 - Diario dos Campos, 7 nov. 2017, p. 1

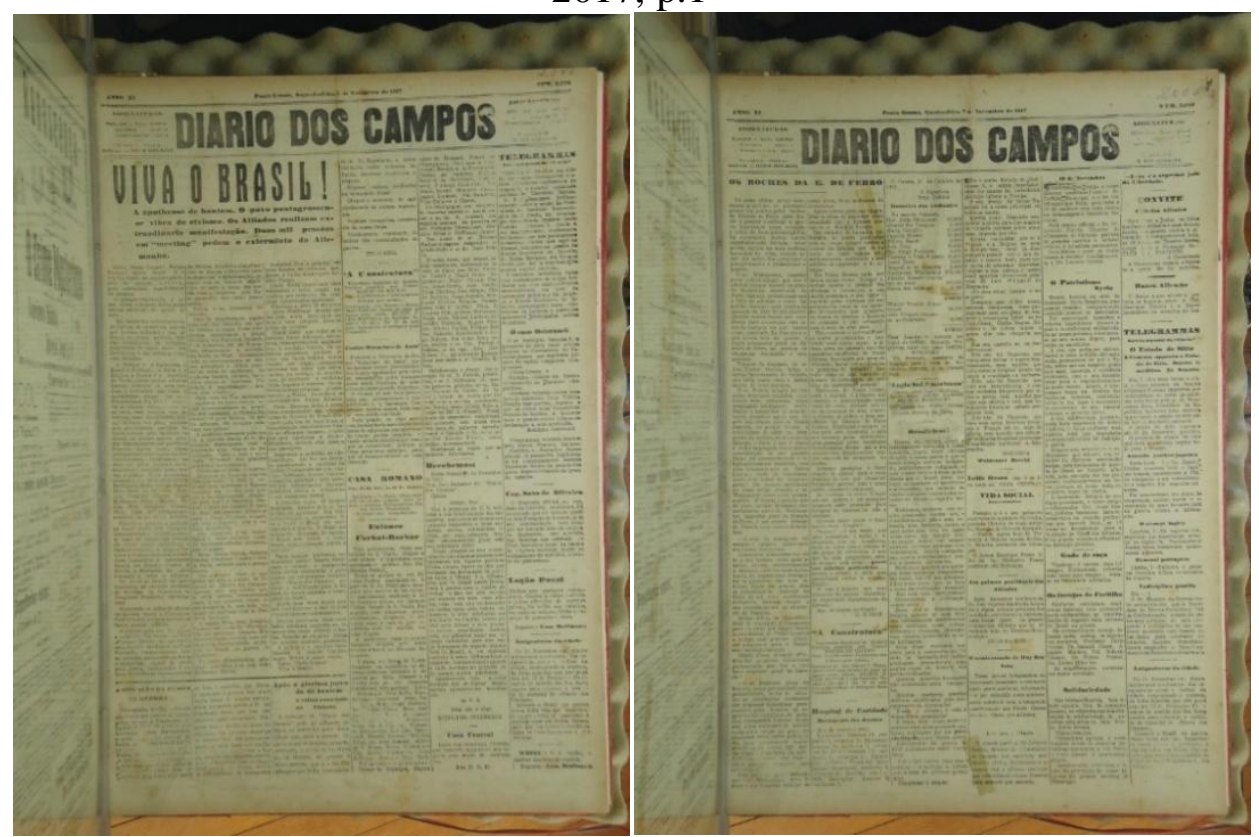

Fonte: Acervo Casa da Memória PG (reprodução).

Em 09 de novembro, o DC informa: "Kerenskicahiu! A Russia fará a paz? Os nacionalistas apoiam o grande Kerenski", defende o título.

Londres, 8 - Os jornais da tarde publicam telegrammas de Petersburgo confirmando a notícia de que os nacionalistas se apoderaram de Petrogrado derrubando o grande Kerenski e arauto da Liberdade do povo russo. Os revolucionários fizeram uma proclamação ao Povo, autodeclarando que vão fazer a paz em separado com a Allemanha. N. R. [nota da redação]: Contra fato há a coligação do Japão, América do Norte, China e talvez do nosso Brasil. (KERENSKI..., 1917, p. 1). 
Figura 4 - Diario dos Campos, 9 nov. 1917, p. 1

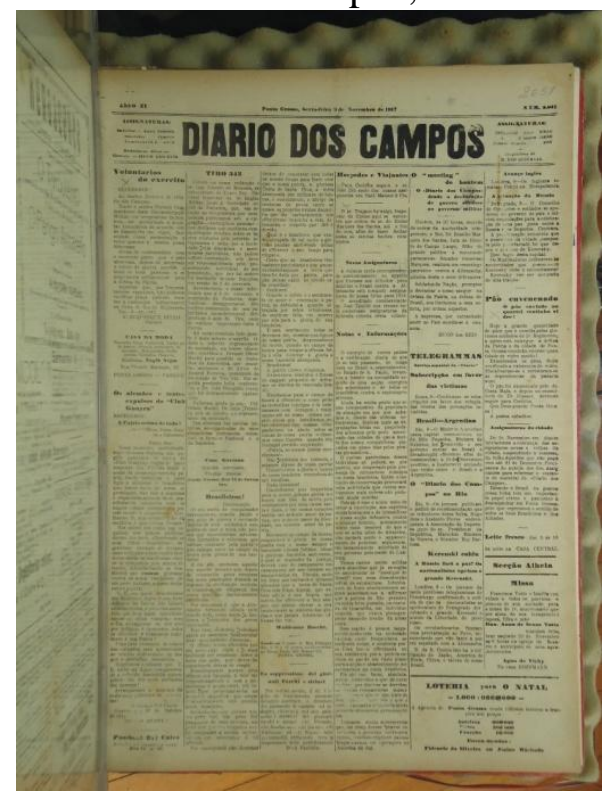

Fonte:Acervo Casa da Memória PG (reprodução).

A edição de 12 de novembro circula com quatro notas do serviço de agência.

(1) O grande estadista russo Kerensky. Kerensky ressurgiu dos mortos acompanhado de um poderoso exército. Nov-York, 12 - comunicam de fonte auctorizada que o grande estadista Alexandre Kerensky, apeiado do poder pelos maximalistas, à frente de importantíssimo exército comandado pelo general Kornillof, marcha sobre Petrogrado. O governo maximalista chefiado por Lenine, sente-se impotente para deter as forças que obedecem a Kerensky. (O GRANDE..., 1917, p. 1).

(2) Revolução em Petrogrado: os soldados russos declaram a guerra santa. New York, 12 - Acaba de irromper com violência em Petrogrado a guerra civil já tendo vários tiroteios. Os soldados russos declaram a guerra santa a todos os inimigos internos e externos da Patria. (REVOLUÇÃO..., 1917, p. $1)$.

(3) Moscou a favor de Kerensky. New York, 12 - (última hora) Toda a guarnição de Moscow e o povo apoiará Kerensky. (MOSCOU..., 1917, p. 1).

(4) Kerensky marcha sobre Petrogrado. O desanimo reina entre os maximalistas. New York, 12 - O General Kerensky a frente de 1.500 .000 homens marcha sobre Petrogrado onde os seus adeptos já aprisionaram vários chefes Maximalistas, que se acham completamente desorientados e se confessam impotentes. Em desespero de causa cortaram várias pontes da Estrada de Ferro Entrechina-Petrogrado. (KERENSKY MARCHA..., 1917, p. 1).

Pelo texto, incluindo a edição de quatro notas com o mesmo tom, e praticamente sem informação concreta diferente, o clima da guerra fria parece mesmo ter iniciado ainda no início da Revolução Russa, quando os sodados bolcheviques tomaram o Palácio de Inverno, com pouca resistência, como revelam registros históricos. Mas não é esse o clima que as agências noticiosas, a partir de New York, passam aos seus 
assinantes. Na edição de 14 de novembro, o DC mantém a linha da notícia anterior. Kerenskyvictorioso, informa título da nota: "Petrogrado, 14 - O general Kerensky entrou em Petrogrado, e toda guarnição se declarou em seu favor. Os maximalistas se vendo perdidos, querem um acordo com o general vitorioso".

Figura 5 - Diario dos Campos, 14 nov. 1917,p. 1

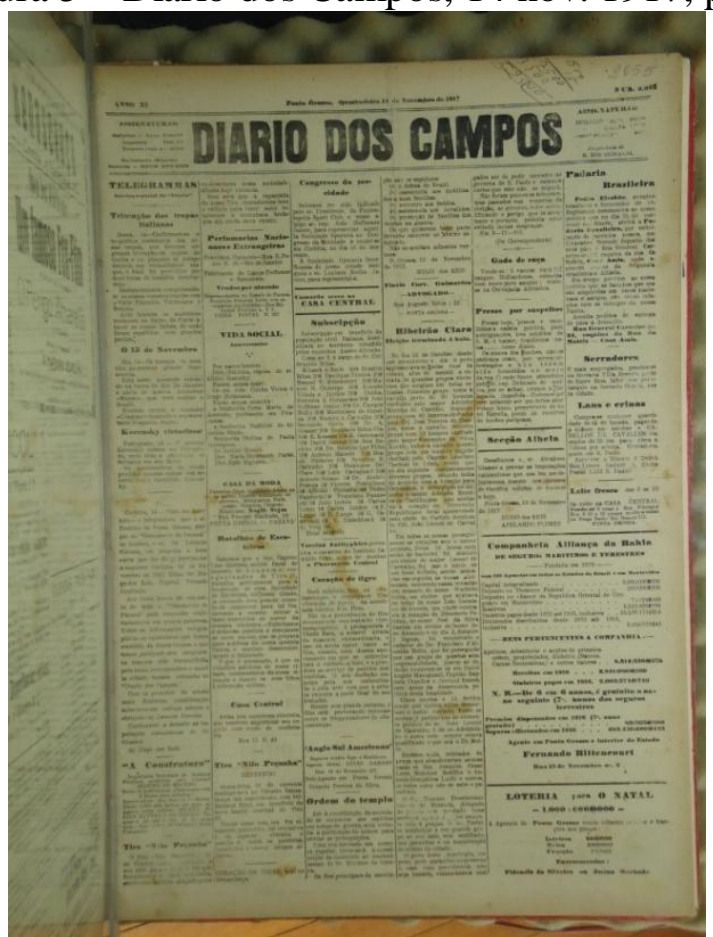

Fonte:Acervo Casa da Memória PG (reprodução).

Em 16 de novembro, o DC reproduz nota sob título de que "faltam notícias da russia". "Pariz, 16 - Não tem vindo notícias de Petrogrado, as agencias telegraphicas que alli funcionavam eram pródigas em despachos e agora emmudederam”, diz. Na edição de 23 de novembro, o DC abre a seção Telegrammas com um destaque: Ressurge o grande Kerenski. E, na edição de 28 de novembro, o título da nota do DC informa sobre A guerra civil na Russia. 
Figura 6 - Diario dos Campos, 16 nov. 1917, p.1 Figura 7 - Diario dos Campos, 23 nov. 1917, p. 1

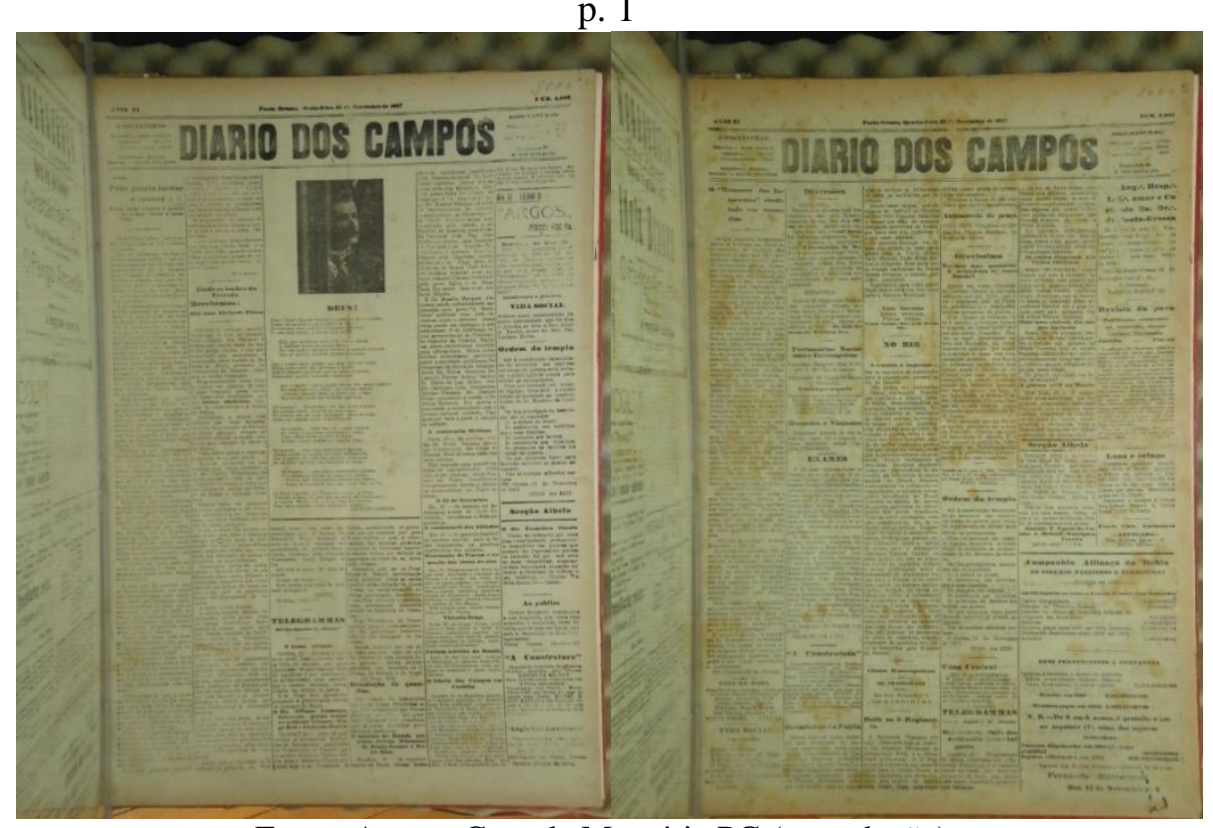

Fonte: Acervo Casa da Memória PG (reprodução).

Em 30 de novembro, o DC traz texto com o título $O$ angú russo. Na edição de 03 de dezembro, o alvo oscila entre uma hipotética resistência do ex-presidente Kerensky e críticas ao líder do movimento revolucionário, Vladimir Lenin. "A Russia reage. Lenine, um vendilhão!", adjetiva a nota publicada.

Figura 8 - Diario dos Campos, 30 nov. 1917, p.1. Figura 9 - Diario dos Campos, 03 dez. 1917, p. 1

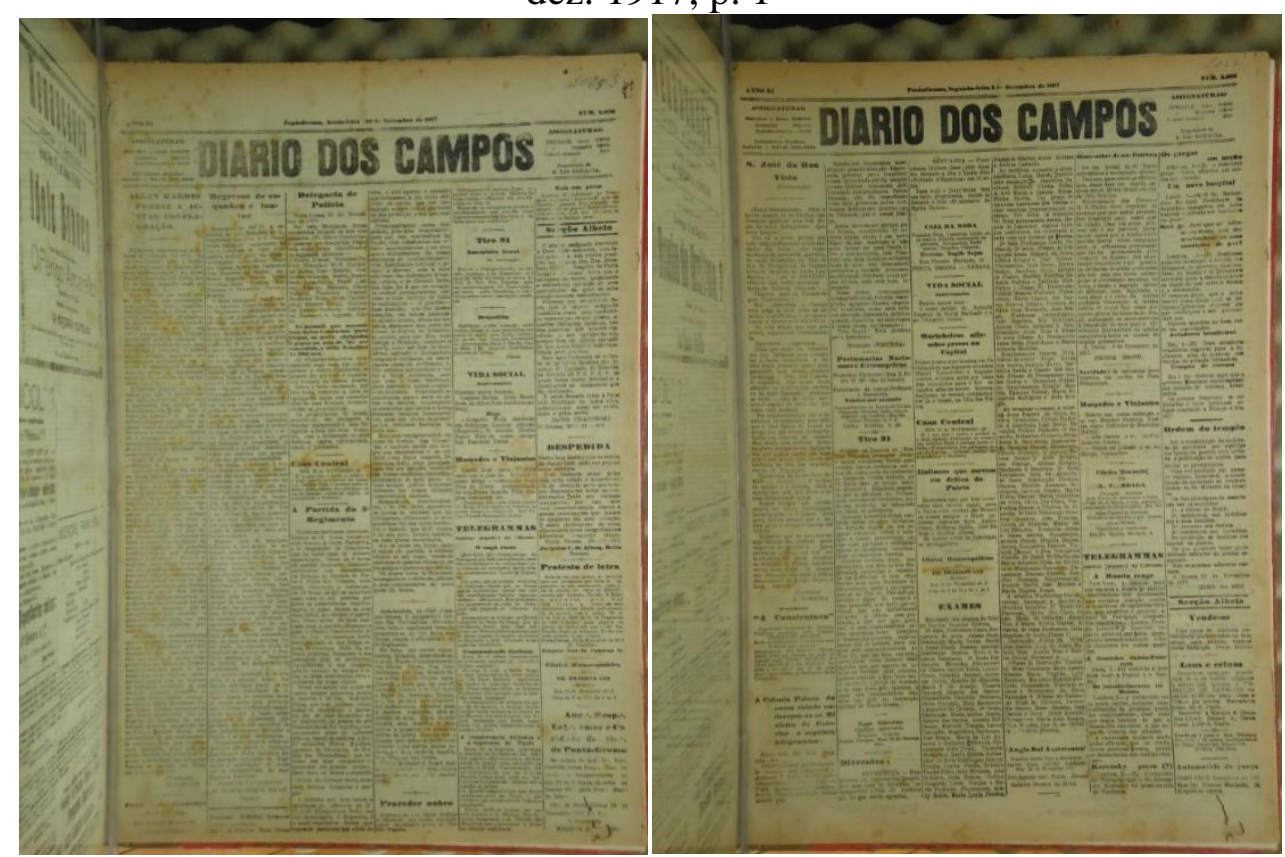

Fonte: Acervo Casa da Memória PG (reprodução). 
No dia 04 de dezembro, o Diário dos Campos veicula texto analítico sobre a "Pobre Polonia, infellizRussia". Em 11 de dezembro, o serviço especial do Diário (Telegrammas) informa que "Kerenski ataca violento". Em outra nota de agência, na mesma página, o DC informa sobre a "paz alemã e russa".

Figura 10 - Diario dos Campos, 04 dez. 1917, p. 1. Figura 11 - Diario dos Campos, 11 dez. 1917, p. 1

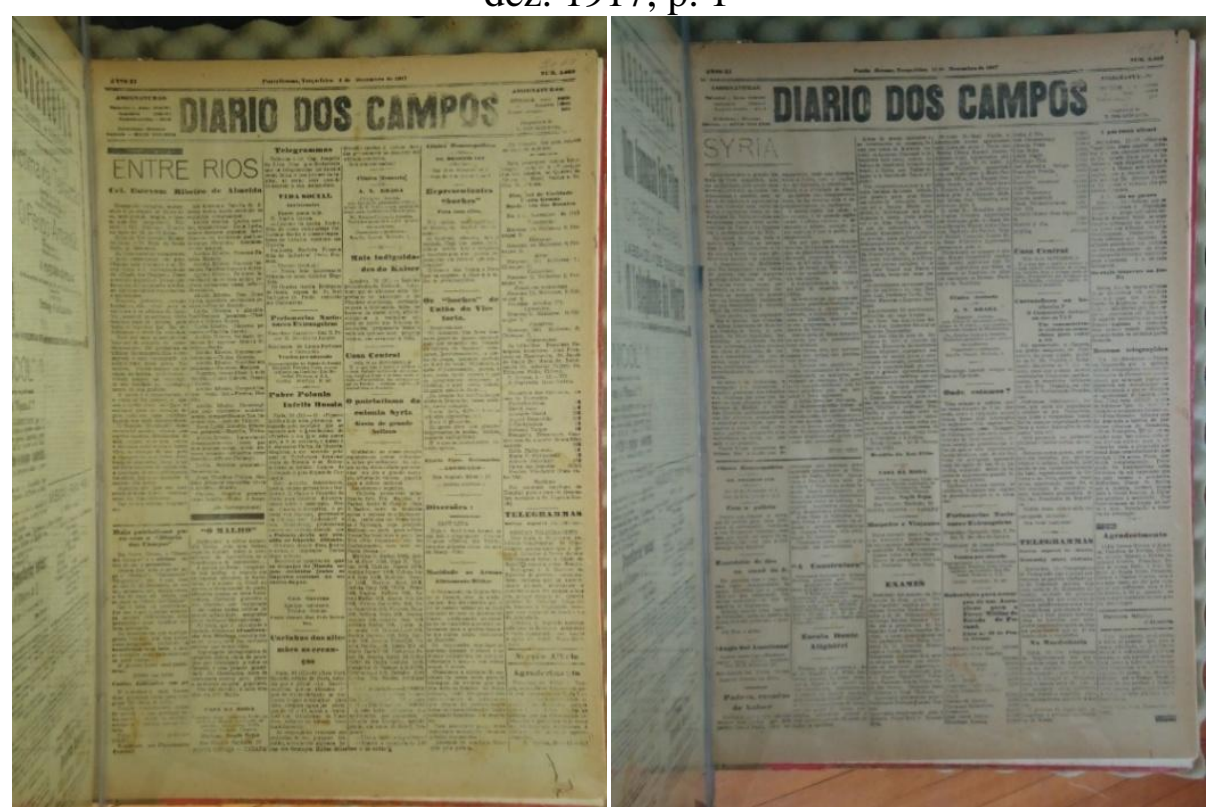

Fonte: Acervo Casa da Memória PG (reprodução).

A última edição de 1917 que veicula material sobre a Revolução Russa é do dia 15 de dezembro, sob o título A embrulhada russa, que apresenta o texto: "Petrogrado, 15 - Sabe-se que o general Kaledine enviou emissários aos maximalistas pedindo para entrar em acordo amigável, afim de cessarem as hostilidades e não haver mais derramamento de sangue". Na mesma página, há outra nota, com o mesmo caráter marcado por uma espécie de interpretação crítica, com descrição adjetivada: Mayonese russa, diz o título, da nota, que segue: "Petrogrado, 15 - O general Scalon, um dos delegados maximalistas que devia trata a paz com os alemães, com quem foi conferenciar, suicidou-se. $\mathrm{O}$ exército central russo recusa reconhecer o alferes Krilenko como seu generalíssimo". 
Figura 12 - Diario dos Campos, 15 dez. 1917, p.1

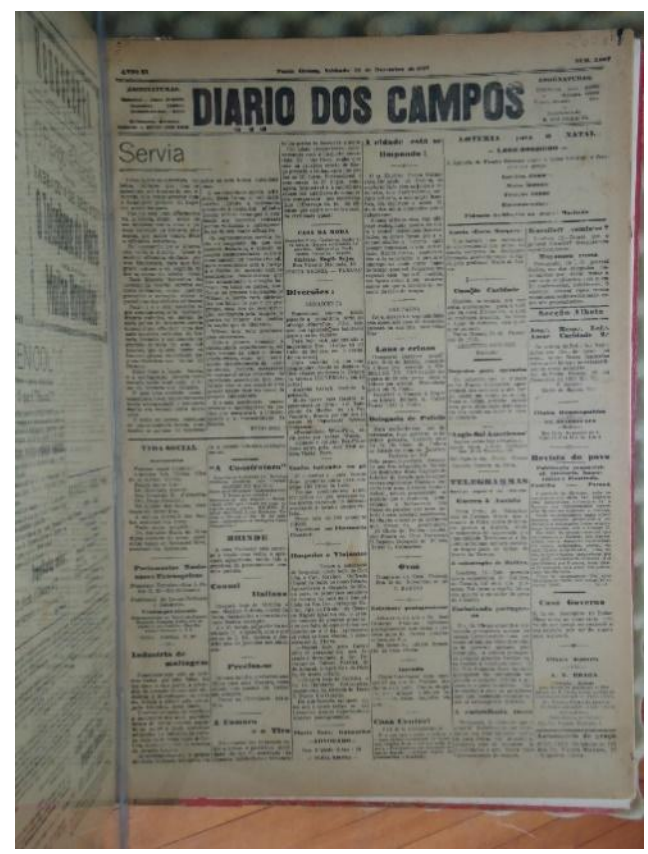

Fonte: Acervo Casa da Memória PG (reprodução).

\section{Considerações finais}

Ao observar a cobertura do Diário dos Campos nos 100 anos do primeiro grande movimento de insurreição operário-camponês, vale considerar a avaliação que um dos dirigentes (TROTSKY, 1997) da revolução fez aos 15 anos de aniversário.

O capitalismo teve necessidade de séculos para se afirmar na luta contra a Idade Média, para elevar a ciência e a técnica, para construir os caminhos de ferro, para estender os fios elétricos... Mas ao socialismo, os seus adversários, quer dizer, os partidos do capitalismo não concedem senão uma década e meia para instalar sobre a terra o paraíso com todo o conforto. Não assumimos tais obrigações. Não assumimos e estabelecemos tais prazos (TROTSKY, 1997, p. 64).

Se considerar as notícias que o DC reproduzia, a partir de telegramas supostamente noticiosos, parece que a pressa tinha outra intenção: marcar uma constante disputa por hegemonia por modos de pensar. O que, na prática, se traduzia - e traduz, ainda hoje - em outra nomeação: a necessidade de gestores de mídia em projetar crenças na eficácia de valores de um modelo secular capitalista, já e ainda, pautado pela crescente desigualdade social em todos os cantos do planeta Terra.

A cobertura jornalística veiculada pelo Diário dos Campos, considerando a análise do que foi veiculado entre julho e dezembro de 1917, foi pautada pelo que era 
divulgado a partir de agências noticiosas, via telegrama. E, eventualmente, editor ou colaboradores que assinam artigos com abordagem assumidamente interpretativa, em geral alinhando-se ideologicamente às decisões de governos ou grupos dominantes.

No caso do DC, o alinhamento veiculado pelas respectivas edições frente à entrada do Brasil na Primeira Guerra - o que só ocorreu em 1917, quando a Rússia estava saindo, a partir da revolução de outubro - mostra uma certa sintonia dos editores com as decisões e escolhas políticas ou econômicas de governos ou vozes hegemônicas no País.

Mais que reproduzir telegramas, o DC ajusta e, por vezes, tenta justificar as escolhas editoriais sobre o que se diz e pensa a respeito das representações imaginárias em relação ao movimento revolucionário que marcou o ano de 1917 na Rússia e no mundo. Talvez porque, para usar as palavras de Antonio Gramsci (2017, p. 714), "muitos não conseguem calcular a mudança histórica que ocorreu na Europa em 1917 e a liberdade que os povos ocidentais conquistaram".

De um modo geral, as notas (via telegrama) do serviço noticioso de agências apresentam uma estrutura breve, com algumas informações e comentários, indicações ou pistas que insinuam elogios, quando se confirma alinhamento da nota com postura pró-guerra assumida pelo Brasil, no caso pós-1917, e com tratamento de dúvida ou ironia, a partir do momento em que a revolução russa avança em ações políticas. Em ambos os casos, como se pode ver nos textos, o que chega ao leitor parece mesmo ser um resultado de uma sintonia entre os materiais de agência e a orientação editorial do jornal.

Não se pode afirmar, e tampouco existem elementos concretos para verificar, se a interpretação, questionamento, suspeita e adjetivos usados são da própria agência noticiosa ou adaptados pelo editor do Diário dos Campos. Fato é que era dessa forma que as edições chegavam aos leitores que o periódico mantinha no ano da Revolução Russa no interior do Paraná. As imagens das páginas e recortes textuais da cobertura do DC evidenciam como os leitores tinham acesso ao que, na versão das agências noticiosas e do editor do Diário, era importante saber e acompanhar a respeito da Revolução de 1917.

\section{Referências}

[ABSOLVIÇÃO]. Diario dos Campos, Ponta Grossa, p. 1, 27 set. 1917. 
BUCHOLDZ, Alessandra. Diário dos Campos: memórias de um jornal centenário. Ponta Grossa: Editora UEPG, 2007.

COSTA, Camilla. $1^{\mathrm{a}}$ greve geral do país, há cem anos, foi iniciada por mulheres e durou 30 dias. In: BBC Brasil. São Paulo: BBC, 28 abr. 2017. Disponível em: <http://www.bbc.com/portuguese/brasil-39740614>.Acesso em: 05 maio 2017.

DEMOCRACIA russa. Diario dos Campos, Ponta Grossa, p. 1, 14 ago. 1917.

DIÁRIO dos Campos. Ponta Grossa: Editora Diário dos Campos, 1917. Acervo digital da Casa da Memória de Ponta Grossa.

DVINSKI resistirá. Diario dos Campos, Ponta Grossa, p. 1, 10 set. 1917.

A EMBRUlHADA russa. Diario dos Campos, Ponta Grossa, p. 1, 15 dez. 1917.

FALTAM notícias da Russia. Diario dos Campos, Ponta Grossa, p. 1, 16 nov. 1917.

GADINI, S. L. Desafios de pesquisa em Jornalismo Cultural: estratégias metodológicas para compreender os processos editoriais no campo cultural. Revista FAMECOS, Porto Alegre, v. 17, n. 1, p. 28-35, [jan./abr.] 2010. Disponível em: $<$ http://revistaseletronicas.pucrs.br/ojs/index.php/revistafamecos/article/view/6876>. Acesso em: 20 mar. 2017.

GRAMSCI, Antonio. Rússia. In: LIGUORI, Guido; VOZA, Pasquale (Org.). Dicionário gramsciano. São Paulo: Boitempo, 2017, p. 12-26.

O GRANDE estadista russo Kerensky. Diario dos Campos, Ponta Grossa, p. 1, 12 nov. 1917.

GREVE na Russia. Diario dos Campos, Ponta Grossa, p. 1, 10 out. 1917.

KERENSKI cahiu. Diario dos Campos, Ponta Grossa, p. 1, 09 nov. 1917.

KERENSKY marcha sobre Petrogrado. Diario dos Campos, Ponta Grossa, p. 1, 12 nov. 1917.

KERENSKY victorioso. Diario dos Campos, Ponta Grossa, p. 1, 14 nov. 1917.

LARANJEIRA, Alvaro N. A Revolução Russa na imprensa brasileira (1917). Correio do Povo, Porto Alegre, 14 out. 2017. Caderno de Sábado, p. 3. Disponível em: <https://www.slideshare.net/tyromello/revoluo-russa-80841548>. Acesso em: 14 out. 2017.

MAYONESE russa. Diario dos Campos, Ponta Grossa, p. 1, 15 dez. 1917. 
MAIS uma derrota alemã. Diario dos Campos, Ponta Grossa, p.1, 19 out. 1917.

MOSCOU a favor de Kerensky. Diario dos Campos, Ponta Grossa, p. 1, 12 nov. 1917.

PINTO, Elizabete Alves. A população de Ponta Grossa a partir do registro civil: 1889 - 1920. 1980. 242 f. Dissertação (Curso de Pós-Graduação em História do Brasil) Universidade Federal do Paraná, Curitiba, 1980. Disponível em: $<$ http://acervodigital.ufpr.br/bitstream/handle/1884/27818/D\%20-

$\%$ 20PINTO,\%20ELISABETE\%20ALVES.pdf?sequence=1\&isAllowed=y $>$. Acesso em 20/03/2017.

PONTES, Felipe; GADINI, Sérgio. Combates e planejamento em uma cidade objetivada: Ponta Grossa (PR) como noticia no Diário dos Campos 1910-1923. Revista Publicatio, Ponta Grossa v. 19, n. 2, [jan./jun.] 2011. Disponível em: <http://www.revistas2.uepg.br/index.php/sociais/article/view/3364>. Acesso em: 20 mar. 2017.

PONTES, Felipe Simão; SILVA, Gislene. Mídia noticiosa como material de pesquisa: recursos para a pesquisa de produtos jornalísticos. In: BOURGUIGNON, Jussara Ayres; OLIVEIRA JUNIOR, Constantino Ribeiro de (Org.). Pesquisa em Ciências Sociais: interfaces, debates e metodologias. Ponta Grossa: Toda palavra, 2012, p. 15-32.

RETIRADA austro-allemã. Diario dos Campos, Ponta Grossa, p. 1, 5 ago. 1917.

REVOLUÇÃO em Petrogrado. Diario dos Campos, Ponta Grossa, p. 1, 12 nov. 1917.

A SITUAÇÃO na Russia. Diario dos Campos, Ponta Grossa, p.1, 11 set. 1917.

A SITUAÇÃO russa. Diario dos Campos, Ponta Grossa, p. 1, 10 set. 1917.

TROTSKY, Leon. A revolução permanente na Rússia. Lisboa: Antidoto, 1977.

VALENZUELA, Javier. Las mujeres bolcheviques que hicieron la Revolución de 1917.

TintaLibre, octubre 2017, n. 51, p. 38-46. Madrid: TintaLibre, 2017.

Submetido em: 16.04.2018

Aprovado em: 23.06.2018 